\title{
Influence of Physical Exercise on the Dialytic Adequacy Parameters of Patients on Hemodialysis
}

\author{
Alicia García Testal, ${ }^{1}$ ( Rafael García Maset, ${ }^{1}$ David Hervás Marín, ${ }^{2}$ \\ Borja Pérez-Domínguez, ${ }^{3}$ Pilar Royo Maicas, ${ }^{1}$ Inmaculada Soledad Rico Salvador, ${ }^{1}$ \\ Erika Meléndez-Oliva, ${ }^{3}$ Javier Molina Aracil, ${ }^{4} \mathrm{M}^{\mathrm{a}}$ José Murgui Chiva, ${ }^{4}$ \\ Olga Del pozo Blanco, ${ }^{4}$ Pau Olagüe Díaz, ${ }^{1}$ Jose Enrique Fernández Najera, ${ }^{1}$ \\ Eduardo Torregrosa De Juan, ${ }^{1}$ Caterina Benedito Carrera, ${ }^{1}$ and Eva Segura-Orti ${ }^{3}$ \\ ${ }^{1}$ Nephrology Service, Hospital de Manises, ${ }^{2}$ Biostatistics Unit, Instituto de Investigación Sanitaria La Fe, \\ ${ }^{3}$ Physiotherapy Department, Universidad Cardenal Herrera-CEU, CEU Universities and ${ }^{4}$ Rehab and \\ physiotherapy service, Hospital de Manises, Valencia, Spain
}

\begin{abstract}
It has been suggested that physical exercise in chronic hemodialysis could improve dialysis dose and reduce postdialysis rebound. A randomized controlled trial was performed to compare a group of patients doing physical exercise during the first $2 \mathrm{~h}$ of hemodialysis sessions and another group doing physical exercise at home. The descriptive variables, dialysis doses measured by $\mathrm{KtV}$, and rebounds (urea, creatinine, potassium, phosphorus), were recorded. For 69 patients: the mean $\mathrm{KtV}$ was 1.84 ; the 30 -min rebound of creatinine was $32.37 \%$, urea $24.39 \%$, potassium $15.31 \%$, and
\end{abstract}

phosphorus $51.29 \%$. For each patient, the basal measurement was compared with those determined when performing physical exercise; no statistically significant differences were observed between the changes determined to dose and rebound in the group with hemodialysis exercise compared to those of the home exercise group. In conclusion, performing physical exercise during the first 2 hours of hemodialysis sessions neither lowered postdialysis molecules rebound nor improved dialysis dose. Key Words: Creatinine, Exercise, Potassium, Renal dialysis, Urea.
The advanced age of many patients with chronic renal disease receiving hemodialysis (HD) treatment, along with high comorbidity, neuropathy, uremic myopathy, altered protein catabolism, anemia, and the forced sedentary lifestyle of renal replacement therapy, lead to progressively reducing patients' physical capacity. At the heart of this process lie frequent muscular alterations that limit patients' functional capacity. Interventions are applied to preserve these patients' physical capacity and to avoid dependency (1-9). Different physical exercise (PE) patterns have been developed that can be done at home, in specialized centers on nondialysis days, or during HD sessions. The last option is the most convenient one as it helps them to

Received July 2018; revised August 2018; accepted September 2018.

Address correspondence and reprint requests to Alicia García Testal, Servicio de Nefrología, Hospital de Manises, Av. de la Generalitat Valenciana, 50, 46940 Manises, Valencia, Spain. Email: agtestal@gmail.com continue with $\mathrm{PE}$, and it allows their vital signs to be controlled while performing PE (10). The most suitable kind of $\mathrm{PE}$ is the exercises that combine aerobics and muscular stamina (8).

Studies of international prominence have demonstrated that dialysis dose is related with patient prognosis. A URR (urea reduction ratio) of $65-75 \%$ or a $\mathrm{Kt} / \mathrm{V}$ of $1-1.3$ per session in the patients with three HD sessions a week obtains the best dose/morbidity and mortality ratio. It has also been verified that high dialysis doses do not improve survival (11-15). These calculations are done with the measurements taken at the end of the sessions. However, it is known that after dialysis the SUN (serum urea nitrogen) rebounds up to figures that cannot be explained only by urea generation, nor can this process be explained by the monocompartmental model. These observations suggest that urea sequestration takes place in another compartment during dialysis. It was previously thought that urea sequestration occurred in the intracellular 
space, but it is now readily accepted that it is found in tissues. Muscles are the main tissues involved, which contain a high total body proportion of water and, therefore of urea, but muscles receive a lower percentage of cardiac expense. The rate at which these tissues transfer urea to blood is low $(16,17)$. When dialysis ends, the continuous movement from the sequestrating compartment to the accessible compartment causes the postdialysis urea rebound; this has been measured in several studies and has shown values of around 20\% (8-13). Most rebound disappears after 30-60 min; postdialysis SUN could be measured at this time, and the true urea reduction rate could be calculated, which would be lower than the measure taken at the end of dialysis (18).

Different authors have pointed out the factors related with higher rebounds, such as dialysis efficiency, recirculation, venous access, the black race, masculine gender, being older, higher ultrafiltration, and lower systolic blood pressure. An inverse relationship has also been found with the volume of distributed urea and congestive heart failure (17,19-21). Our group confirms that the urea rebound increases with age, $\mathrm{Kt} / \mathrm{V}$, recirculation and hypotension, and also lowers in those patients on online hemodiafiltration (22).

In 1998, Smye used mathematical models to suggest that the PE performed during HD would improve dialysis dose by mobilizing the molecules sequestered in the muscular compartment. The model is based on high-flow compartments existing (3.8 L/min: lungs, blood, heart, brain, small-sized organs, and portal system) in parallel with lowflow compartments $(1 \mathrm{~L} / \mathrm{min}$ : bone, muscle, skin, and fatty tissue). The mixture of blood from both compartments would be responsible for the postdialysis rebound to a great extent. It is considered that the perfusion of low-flow compartments slightly increases while performing $\mathrm{PE}$, going from 1.1 to $7.1 \mathrm{~L} / \mathrm{min}$ at $20-30 \mathrm{~min}$, while the perfusion of the high-flow ones and the venous access remain constant. Since it has been estimated that this effect continues later, performing PE during part of an HD session could help to improve clearance, rebound and dialysis dose. To date, however, very few studies have analyzed this intervention and the existing ones offer contradictory results (23-27).

Conversely, many studies have demonstrated the benefits of PE programs in patients on HD (28-33).

The objective of the present study is to check the effect of $\mathrm{HD}$ patients performing $\mathrm{PE}$ on dialysis dose and postdialysis molecules rebound.

\section{PATIENTS AND METHODS}

A randomized controlled trial that compared two groups of patients who practiced PE was conducted from January to April 2016. The study sample was formed by the patients who went to the Haemodialysis Unit at the Manises Hospital in the province of Valencia (Spain).

The inclusion criteria were having been on chronic HD treatment for 3 months or more, remaining clinically stable during the study, and providing informed consent. The exclusion criteria were having suffered from myocardial infarction in the 6 weeks running up to the study, unstable angina, amputation of lower limbs above the knee with no prosthesis, cerebral vascular disease like stroke or transitory ischemia, musculoskeletal or respiratory alterations that worsen with $\mathrm{PE}$, unable to perform functional physical tests, or being a venous access carrier in lower limbs.

The participants were divided into two groups: an intervention group doing intradialysis PE (Group ID) and another intervention group doing $\mathrm{PE}$ at home (Group DO). To avoid gender or age biases that could confound the final program results, the two groups were homogeneous according to these characteristics. Randomization was done using the website: www.randomization.com.

The two PE programs lasted 3 months, with a frequency of three sessions/week and $60 \mathrm{~min} / \mathrm{session}$. A team of physiotherapists assessed the subjects before programs began. The Group ID PE program combined PE with force exercises with aerobics, which took place during the first $2 \mathrm{~h}$ of HD sessions. A 5-min session took place first to warm up the muscles to be worked on a posteriori. The first part of the program consisted of force exercises using progressive stamina-based isotonic and isometric exercises with lower limbs. Total duration lasted up to $30 \mathrm{~min}$. The second part consisted of aerobics for a maximum 30-min period on bicycles adapted to an HD chair/bed (Motomed Letto), which allowed movement stamina to be graduated. Sessions ended with 5 min time for patients to relax and stretch the involved muscles. The program was managed and supervised by several physiotherapists and trained staff members from the hospital's HD Unit. Patients were taught to perform PE either independently or with minimum assistance. The HD session could be done simultaneously because PE worked the lower limbs. While the exercise program was underway, heartbeat and blood pressures were monitored as indicators of hemodynamics. The patients in the Group DO did PE at home 3 days a week on non-HD days. A physiotherapist taught them patterns for PE intensity, frequency 
and type, and patients' self-monitoring with a daily activity diary. This program used similar exercises to those done by the ID Group.

The determined variables were: age, gender, time on HD in months, renal disease etiology, venous access (VA) type, race, residual $\mathrm{KtV}$, and $\mathrm{HD}$ type. During the HD session, the following variables were recorded: blood pressure at the beginning and blood pressure at the end in $\mathrm{mmHg}$, VA recirculation as a $\%$ using a BTM (blood temperature monitor), ultrafiltration in liters, session duration in minutes, dialysis filter, blood flow in $\mathrm{mL} / \mathrm{min}$, and dialysate flow in $\mathrm{mL} / \mathrm{min}$. Dialysis dose and molecules rebound were calculated during a baseline session before the PE program commenced, and also during another session 12 weeks into the PE program. Samples were taken in both cases during the second weekly session. The following were calculated as dialysis dose indices: URR (URR: pre-post/preurea) and second-generation KtV Daugirdas $(\mathrm{Kt} / \mathrm{V}=-\ln ((\mathrm{C} 2 / \mathrm{C} 1)-(0.008 * \mathrm{~T}))+(4-3.5$ $*(\mathrm{C} 2 / \mathrm{C} 1)) * \mathrm{UF} / \mathrm{P})$, both at the end and after $30 \mathrm{~min}$. The rebounds of urea, creatinine, potassium and phosphorus were calculated following the formula (19):

Rebound $(\%)=100^{*}(\mathrm{CR}-\mathrm{C} 2) / \mathrm{C} 2$.

C2: Determined by a blood sample taken when the session ended.

CR: Determined by a blood sample taken $30 \mathrm{~min}$ after the session ended.

The following determinations were made: urea by a Roch-Ramel enzymatic reaction, creatinine by a Jaffé colorimetric reaction, phosphorus by a Daly and Ertinghausen colorimetric reaction, and potassium by indirect potentiometry using a selective electrode of the Advia 1800 analyzer.

The Research Ethics Committee and the center's Research Committee favorably approved this research. Informed consent was obtained from all the participants. The present experimental protocol respected the fundamental principles set out in the Declaration of Helsinki, in the Council of Europe Convention about Human Rights and Biomedicine, and in the UNESCO's Universal Declaration about the Human Genome and Human Rights. It met the requirements set out in Spanish legislation in accordance with the Spanish Data Protection Act of 15/1999, of 13 December, in the biomedical research, personal data protection and bioethics area.

Sample size was estimated by assuming a $15 \%$ mean rebound value with a standard deviation of 3 . We estimated that with a minimum of $3 \%$ with $80 \%$ statistical power and a type I error of $5 \%$,
30 patients per group would be necessary to detect reduced rebound. By assuming 20\% extra subjects because of possible losses from mortality, transplant or comorbidity, the final sample size would have to comprise 36 patients in both groups; that is, 72 patients in all.

\section{Statistical analysis}

Data are presented as mean, standard deviation, median and first and third quartiles for the continuous variables, and as relative and absolute frequencies for the categorical variables. The analysis of the PE effects on the rebound percentage and also on $\mathrm{Kt} / \mathrm{V}$ was done using a mixed model of repeated measures with the logarithmic transformation of the rebound values. In the mixed model, a comparison was made to see if the individuals in one of the groups presented a more marked change in the rebound percentage or in the $\mathrm{KtV}$ before and after the intervention than those presented by the individuals in the other group. Those $P$ values below 0.05 were considered statistically significant. All the analyses were done using $\mathrm{R}$ software (version 3.2.1).

\section{RESULTS}

Of the 150 patients on chronic HD treatment at the Manises Hospital, 69 were selected according to the inclusion/exclusion criteria to participate in this study. The causes of the participants' kidney failure are shown in Figure 1. Patients' flow during the study and the causes of loss are provided in Table 1. The characteristics of the patients who remained in the study in each group are shown in Table 2 . Regarding the HD technique, 18 were on online

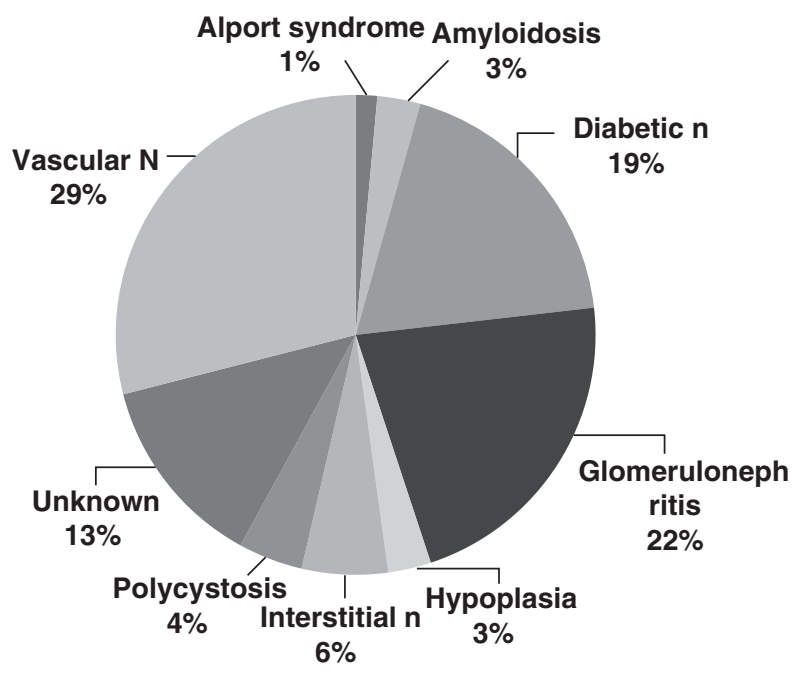

FIG. 1. Kidney failure etiology. 
TABLE 1. Patients included, excluded and causes of losses during the study

\begin{tabular}{lc}
\hline Patients included in the chronic hemodialysis program & 150 \\
No. patients excluded & 23 \\
Did not give consent & 4 \\
Less than 3 months in the program & 54 \\
By exclusion criteria & 69 \\
Patients included when the study began & 33 \\
Physical exercise at home & 36 \\
Physical exercise during intradialysis & 23 \\
Losses during the study & 2 \\
Causes: & 8 \\
Cannot do physical exercise at home & 2 \\
Cardiovascular or respiratory disease & 2 \\
Musculoskeletal disease & 9 \\
Other clinical incidences & 4 \\
The patient no longer wishes to continue & 5 \\
Physical exercise at home & 46 \\
Physical exercise during hemodialysis & 23 \\
Patients included at the end of the study & 23 \\
Physical exercise at home & \\
Physical exercise during intradialysis &
\end{tabular}

TABLE 2. Characteristics of the patients included at the end of the study, as groups

\begin{tabular}{lcc}
\hline & Group DO & Group ID \\
\hline $\begin{array}{l}\text { Females/males } \\
\text { Age in years: mean, median }\end{array}$ & $6 / 17$ & $6 / 17$ \\
(1st, 3rd Q) & $66,70(59,74)$ & $68,71(62,81)$ \\
$\begin{array}{l}\text { Race } \\
\quad \text { Caucasian/Asian/American }\end{array}$ & $22 / 0 / 1$ & $22 / 1 / 0$ \\
$\begin{array}{l}\text { Receiving hemodialysis in } \\
\text { months: mean, median }\end{array}$ & & \\
$\begin{array}{l}\text { (1st, 3rd Q) } \\
\text { Venous access: AVF/CVC }\end{array}$ & $48,34(20,60)$ & $40,31(18,51)$ \\
Residual KtV & $21 / 2$ & $22 / 1$ \\
$\quad$ Mean (SD) & 0.20 & 0.22 \\
Median (1st, 3rd Q) & $0.07(0.00,0.33)$ & $0.06(0.00,0.42)$ \\
CHF & 2 & 1 \\
HD technique: OLHF/HFH/LFH & $8 / 15 / 0$ & $6 / 16 / 1$ \\
\hline
\end{tabular}

$\mathrm{CHF}$, congestive heart failure; $\mathrm{CVC}$, tunneled central venous catheter; AVF, arteriovenous fistula; $\mathrm{HFH}$, high-flow hemodialysis; LFH, low-flow hemodialysis; OLHF, online hemodiafiltration.

hemodiafiltration (OLHF), 48 were on high-flow hemodialysis (HFH), and three on high-efficiency low-flow hemodialysis (LFH). Fresenius FX10 dialyzers $\left(1.8 \mathrm{~m}^{2}\right.$ Cuf $14 \mathrm{~mL} / \mathrm{h} \times \mathrm{mmHg}, \mathrm{KoA}$ $976 \mathrm{~mL} / \mathrm{min}$ ) were used with three patients, FX60 dialyzers $\left(1.4 \mathrm{~m}^{2}\right.$ Cuf $38 \mathrm{~mL} / \mathrm{h} \times \mathrm{mmHg}, \mathrm{KoA}$ $1068 \mathrm{~mL} / \mathrm{min})$ were used with 20 , FX80 $\left(1.8 \mathrm{~m}^{2}\right.$ Cuf $53 \mathrm{~mL} / \mathrm{h} \times \mathrm{mmHg}, \quad \mathrm{KoA} 1394 \mathrm{~mL} / \mathrm{min})$ with 27, FX100 $\left(2.2 \mathrm{~m}^{2}\right.$ Cuf $68 \mathrm{~mL} / \mathrm{h} \times \mathrm{mmHg}, \mathrm{KoA}$ $1429 \mathrm{~mL} / \mathrm{min})$ with 16 and F70S $\left(1.6 \mathrm{~m}^{2}\right.$ Cuf $50 \mathrm{~mL} / \mathrm{h} \times \mathrm{mmHg}, \mathrm{KoA} 774 \mathrm{~mL} / \mathrm{min}$ ) with three. All the patients continued the same technique and dialyzer throughout the study period, except for one patient who started with an FX80 dialyzer before being changed to an FX100 dialyzer. Sessions lasted 235 (11.13) $\mathrm{min}$ and the mean ultrafiltration was 1.97 (1.06) L. The mean blood flow was 397.47 (41.7) $\mathrm{mL} / \mathrm{min}$ and the dialysate flow was 648.83 (74.09) $\mathrm{mL} / \mathrm{min}$. The mean recirculation of accesses was $13 \%$ (4). For the determinations made before implementing the PE program, the mean URR was $79 \%$ (4). The mean $\mathrm{KtV}$ at the end of the session was 1.84 (0.28). The mean URR30 was $74 \%$ and KtV30 was 1.6 when calculated with the sample drawn 30 min after the session ended. Both these values presented significant differences compared to those measured at the end of the session (URR vs. URR30 $P<0.00195 \%$ CI for the difference: $[3.09,6.13]$; KtV vs. KtV30 $P<0.00195 \%$ CI for the difference: $[0.16,0.33])$. The mean rebounds recorded $30 \mathrm{~min}$ after the session ended according to the formula, were: creatinine $32.37 \%$ (27.77), urea $24.39 \%$ (22.02), potassium $15.31 \%$ (10.61), and phosphorus $51.29 \%$ (99.51).

In each patient, the baseline rebound was compared with those determined when performing PE at the end of the study. No statistically significant differences were observed between both determinations in the Group ID vs. those of the Group DO: rebounds for: urea: $p=0.38$; creatinine: $p=0.32$; potassium: $p=0.31$; phosphorus: $p=0.74$.

Table 3 offer the mean values recorded in dialysis dose and molecules rebound before and after both groups did PE exercises.

We did not find any significant differences in the change of either baseline $\mathrm{KtV}(P=0.62)$ or baseline KtV30 $(P=0.25)$ compared to those determined with PE in each Group ID patient, in comparison with the changes noted in the Group DO patients.

The hemodynamics for Group ID remained stable while they did PE during HD sessions. No significant differences were found for: the mean systolic blood pressure when the session started and ended (start $147.9 \mathrm{mmHg}$, end $140.3 \mathrm{mmHg} ; P=$ 0.08 ); diastolic blood pressure (start $62.67 \mathrm{mmHg}$, end $62.00 \mathrm{mmHg} ; P=0.49$ ); the number of intradialysis hypotension episodes between Group ID and Group DO.

\section{DISCUSSION}

The present study started by considering two acknowledged facts: the need to improve physical capacity of those patients in chronic HD programs and the influence of rebound on dialysis dose. The starting point to combine both processes was the mathematic work with which Smye proposed that these two facts could be employed with a positive 
TABLE 3. Mean values of dialysis dose and rebound before and after the program in the physical exercise ${ }^{\dagger}$

\begin{tabular}{|c|c|c|c|c|}
\hline & DO Group & DO Group & ID Group & ID Group \\
\hline & BASELINE & $\mathrm{PE}$ & BASELINE & $\mathrm{PE}$ \\
\hline$\overline{\mathrm{KtV}}$ & 1.85 & 1.82 & 1.86 & 1.87 \\
\hline URR & 79.26 & 79.28 & 79.47 & 79.77 \\
\hline KtV30 & 1.59 & 1.65 & 1.61 & 1.85 \\
\hline URR30 & 74.70 & 76.07 & 74.93 & 76.53 \\
\hline$\%$ of creatinine rebound & 30.36 & 24.48 & 34.20 & 44.77 \\
\hline$\%$ of urea rebound $\%$ & 24.58 & 17.57 & 24.21 & 38.55 \\
\hline$\%$ of potassium rebound & 13.15 & 12.06 & 15.61 & 17.86 \\
\hline$\%$ of phosphorus rebound & 57.05 & 27.90 & 43.84 & 43.02 \\
\hline$\%$ of VA recirculation & 12.85 & 13.16 & 14.55 & 14.16 \\
\hline Blood flow $\mathrm{mL} / \mathrm{min}$ & 396.5 & 400.3 & 397.2 & 395.9 \\
\hline Dialyzed flow $\mathrm{mL} / \mathrm{min}$ & 659 & 655.3 & 634.6 & 646.3 \\
\hline
\end{tabular}

${ }^{\dagger}$ Rebound (19): \% of rebound $=100 *(\mathrm{CR}-\mathrm{C} 2) / \mathrm{C} 2$. C2, blood sample when session ends; CR, sample taken 30 min after ending session; ID Group, group doing intradialysis PE; DO Group, group doing PE at home; PE, physical exercise; VA, venous access.

effect for these patients (23). The present study was conducted with the objective of checking if a PE program could have an effect on postdialysis molecules rebound and dialysis dose.

We believe that after reviewing its characteristics, the sample is representative of the Spanish population on chronic HD treatment (34). For venous access, the AVF percentage fell within the recommended ones, with adequate flow and recirculation. The mean session time and dialysis dose met current guideline recommendations $(35,36)$. Thus, we consider that our HD sessions took place as usual to give the results obtained here.

The implementation of PE for patients on chronic $\mathrm{HD}$ is an emerging issue at present. The prevention of the usual complications in these patients and the need to preserve their capacity and independence have moved different groups to work on this issue. However, difficulties can present both with the participating health personnel and with the patients.

The PE performed in our study was implemented by the HD Unit personnel (nurses) or by the hospital's physiotherapists. Former studies have shown that more patients get involved if the personnel who usually attend them offer participation in the program, rather than external research personnel who work in a dialysis unit for a limited time $(30,37,38)$. In our study, it took 2 weeks to train the staff members, who were not completely sure about implementing the PE program and thought that it would considerably increase their work burden, by the physiotherapist researcher.

On the one hand, it is worth reflecting on the candidate patients to be included in a PE program in an HD Unit: Concomitant disease could be a frequent contraindication for $\mathrm{PE}$ for patients in a chronic HD program as half of the patients who come to our unit were in this situation. The number of patients who do not wish to participate in a PE program is another interesting point. In our study more than one third of the selected patients did not provide informed consent or dropped out while the program was underway. On the other hand, we wish to stress that other patients who did not comply with certain criteria, and could not be included, had repeatedly shown an interest in participating in a PE program.

The baseline mean urea rebound in our sample once again provided much higher values than those described in former studies $(17-21,39,40)$. A rebound of this quantity implies that the dialysis dose achieved at the end of the sessions significantly lowered $30 \mathrm{~min}$ after it ended, which we checked when comparing our $\mathrm{KtV}$ and final URR values with the rebound calculated with the sample taken after $30 \mathrm{~min}$. Similar results have been obtained in studies by Maduell, Spiegel, and Leblanc $(20,21,39,40)$. Although the rebounds of creatinine, potassium, and phosphorous have been less studied, we were able to quantify them here and they were even higher than the urea rebound. These figures should be considered when clinically evaluating the results at the end of an HD session.

The rebound results for Group ID vs. Group DO showed no significant differences. Nor did we observe differences between both groups for the changes in KtV. Since Smye's publication in 1998 (23) about the possible beneficial effects of PE on dialysis dose, different studies have been published with contradictory results. In 1999, Kong (24) published results from a study conducted in the United Kingdom which showed that 60 min of ID PE significantly improved the rebounds of urea, creatinine, and potassium, and also KtV. These findings support Smye's theory and the most efficient dialysis is that which combines PE during sessions. In 2002, 
Sun (China) published some similar results (25). In 2004 in Australia, Vaithilingam published positive results about enhanced phosphorus clearance in patients who did ID PE (41). Parson in 2006 (Canada) (42) and Giannaki in 2011 (Greece) (43) informed that dialysis dose improved with ID PE. Nevertheless, not all the authors report results that fall in line with these. In 2005, Caner (27) reported the lack of any effect of PE on the rebounds of urea, potassium, or creatinine, nor on urea clearance. Similarly, and more recently, Orcy (2014, Brazil) (26) and Musavian (2015, Iran) (44) have informed that there were no changes with ID PE.

All the above-cited studies worked with small sample sizes, between 10 and 20 patients, and most included short follow-up periods. They all included $\mathrm{PE}$ at different session times and for distinct period lengths, which makes comparing them difficult. Our study size is bigger, and we included a longer follow-up period and results about both dialysis dose and the postdialysis rebound of four molecules. Our results suggest that ID PE has no effect when practiced during the first two session hours on dialysis dose and postdialysis rebound. Thus our results support those reported by Caner (27), Orcy (26), and Musavian (44).

Our study is not without its limitations which can bias its results. First of all, the groups were formed only homogeneously with gender and age. Secondly, the sample size was limited because some patients did not sign the informed consent, some losses were due to disease, and some people voluntarily dropped out. Finally, like the majority of previous studies, performing PE during HD sessions was done during the first $2 \mathrm{~h}$ of sessions; Smye (23) proposed that the end of the session could be the time with the strongest effect on reducing molecules rebound. We decided to not consider this time so that hemodynamic instability would cause no bias, which might appear at the end of sessions in relation to the ultrafiltered volume. It is possible that in the 2 hours after exercise, during the hemodialysis session, in which the rest was performed, the retention of molecules in the muscular compartment could happen again. As a result of this, at the end of the session it would show the same rebound as if they had not exercised. We believe that Smye's theory could be true and, therefore, we propose conducting future studies to check if rebound can lower and dialysis dose can increase while practicing $\mathrm{PE}$ towards the end of HD sessions. We also believe that it is necessary to continue investigating the molecules sequestration compartments or those from where rebounds originate. In a previous study (22), we provided information about there being no association between the fat-free mass measured by bioimpedance and rebound figures. These former findings and those reflected here could question the leading role of muscle tissue as the main sequestration compartment.

Decreasing the rebound of molecules could improve the dose of dialysis and offer a better future to patients, either by improving survival or by reducing the duration of dialysis sessions, which is so worrying to patients. On the other hand, the benefits of physical exercise in these patients could improve their prognosis and quality of life in relation to their physical state. Therefore, the different clinical implications of the present study push us to think that it is necessary to continue with these investigations.

\section{CONCLUSION}

Performing physical exercise during the first $2 \mathrm{~h}$ of a hemodialysis session neither lowered postdialysis molecules rebound nor improved dialysis dose. Further studies should be carried out on other types of interventions to improve these results.

Acknowledgment: We thank the nursing staff members in the Haemodialysis Unit at the Manises Hospital for their collaboration.

Conflict of Interest: None.

\section{REFERENCES}

1. Painter P. Physical functioning in end-stage renal disease patients: update 2005. Hemodial Int 2005;9:218-35.

2. Johansen KL. Exercise in the end-stage renal disease population. J Am Soc Nephrol 2007;18:1845-54.

3. Odden MC. Physical functioning in elderly persons with kidney disease. Adv Chronic Kidney Dis 2010;17:348-57.

4. Sakkas GK, Ball D, Mercer TH, Sargeant AJ, Tolfrey K, Naish PF. Atrophy of non-locomotor muscle in patients with end-stagerenal failure. Nephrol Dial Transplant 2003;18: 2074-81.

5. Esteve V, Junqué A, Moreno $\mathrm{F}$ et al. Beneficios del ejercicio físico de baja intensidad durante la sesión de hemodiálisis en el paciente anciano. Nefrologia 2015;35:385-94.

6. Deligiannis A. Exercise rehabilitation and skeletal muscle benefits in hemodialysis patients. Clin Nephrol 2004;61 (Suppl 1):S46-50.

7. Painter PL, Nelson-Worel JN, Hill MM et al. Effects of exercise training during hemodialysis. Nephron 1986;43:87-92.

8. Segura-Ortí E. Ejercicio en pacientes en hemodiálisis: Revisión sistemática de la literatura. Nefrologia 2010;30:236-46.

9. Kouidi E, Grekas D, Deligiannis A, Tourkantonis A. Outcomes of long-term exercise training in dialysis patients: comparison of two training programs. Clin Nephrol 2004;61 (Suppl 1):S31-8. 
10. Konstantinidou E, Koukouvou G, Kouidi E, Deligiannis A, Tourkantonis A. Exercise training in patients with end-stage renal disease on hemodialysis: comparison of three rehabilitation programs. J Rehabil Med 2002;34:40-5.

11. Lowrie EG, Laird NM, Parker TF, Sargent JA. Effect of the hemodialysis prescription on patient morbidity - report from the National Cooperative Dialysis Study. $N$ Engl J Med 1981;305:1176-81.

12. Held PJ, Port FK, Wolfe RA et al. The dose of hemodialysis and patient mortality. Kidney Int 1996;50:550-6.

13. Gotch FA, Sargent JA. A mechanistic analysis of the National Cooperative Dialysis Study (NCDS). Kidney Int 1985;28:526-34.

14. Port FK, Ashby VB, Dhingra RK, Roys EC, Wolfe RA. Dialysis dose and body mass index are strongly associated with survival in hemodialysis patients. J Am Soc Nephrol 2002;13:1061-6.

15. Eknoyan G, Beck GJ, Cheung AK et al. Effect of dialysis dose and membrane flux in maintenance hemodialysis. N Engl J Med 2002;347:2010-9.

16. Alquist M, Thysell H, Ungerstedt U, Hegbrant J. Development of a urea concentration gradient between muscle interstitium and plasma during hemodialysis. Int J Artif Organs 1999;22:811-5.

17. Daugirdas JT, Greene T, Depner TA et al. Factors that affect postdialysis rebound in serum urea concentration, including the rate of dialysis: results from the HEMO study. J Am Soc Nephrol 2004;15:194-203.

18. Daugirdas JT. Capítulo 3: bases fisiológicas y modelo cinético de la urea. In: Daugirdas JT, Blake PG, Ing TS, eds. Manual de Diálisis, 5th edn. Barcelona, España: Wolters Kluwer, 2015.

19. Maduell F, Sigüenza F, Caridad A, López-Menchero R, Miralles F, Serrat F. Efecto rebote de la urea: influencia del volumen de distribución de la urea, tiempo de diálisis y aclaramiento del dializador. Nefrologia 1994;14:189-94.

20. Spiegel DM, Baker PL, Babcock S, Contiguglia R, Klein M. Hemodialysis urea rebound: the effect of increasing dialysis efficiency. Am J Kidney Dis 1995;25:26-9.

21. Leblanc $M$, Charbonneau $R$, Lalumière $G$, Cartier $P$, Déziel C. Postdialysis urea rebound: determinants and influence on dialysis delivery in chronic hemodialysis patients. Am J Kidney Dis 1996;27:253-61.

22. García Testal A, Hervás D, García Maset R et al. Update on postdialysis rebound by a new technology in hemodialysis. Ther Apher Dial 2017;21:473-7. https://doi.org/10.1111/17449987.12545.

23. Smye S, Lindley E, Will E. Simulating the effect of exercise on urea clearance in hemodialysis. J Am Soc Nephrol 1998;9:128-32.

24. Kong CH, Tattersall JE, Greenwood RN, Farrington K. The effect of exercise during haemodyalisis on solute removal. Nephrol Dial Trasplant 1999;14:2927-31.

25. Sun Y, Chen B, Jia Q, Wang J. The effect of exercise during hemodialysis on adequacy of dialysis. Zhonghua Nei Ke Za Zhi 2002;41:79-81.

26. Orcy R, Antunes MF, Schiller T, Seus T, Böhlke M. Aerobic exercise increases phosphate removal during hemodialysis: a controlled trial. Hemodial Int 2014;18:450-8. https://doi. org/10.1111/hdi.12123.
27. Caner C, Ozlem S, Yavuz Y et al. The effects of exercise during hemodialysis on adequacy. Hemodial Int 2005;9:77. https://doi.org/10.1111/j.1492-7535.2005.1121r.x.

28. Ostir GV, Volpato S, Fried LP, Chaves P, Guralnik JM. Reliability and sensitivity to change assessed for a summary measure of lower body function results from the Women's health and aging study. J Clin Epidemiol 2002;55:916-21.

29. Greenwood SA, Lindup H, Taylor K et al. Evaluation of a pragmatic exercise rehabilitation programme in chronic kidney disease. Nephrol Dial Transplant 2012;27 (Suppl 3): iii126-34. https://doi.org/10.1093/ndt/gfs272.

30. L. Ortega. Comparison of two exercise programs for hemodialysis patients, intradialysis vs home based program. Absolute and relative reliability of physical performance (Doctoral dissertation). Valencia: Universidad CEU Cardenal Herrera. Facultad de Ciencias de la Salud, 2017.

31. Bohannon RW. Sit-to-stand test for measuring performance of lower extremity muscles. Percept Mot Skills 1995;80:163-6.

32. Segura-Orti E, Martinez-Olmos FJ. Test-retest reliability and minimal detectable change scores for sit-to-stand-to-sit tests, the six-minute walk test, the one-leg heel-rise test, and handgrip strength in people undergoing hemodialysis. Phys Ther 2011;91:1244-52.

33. ATS Committee on Proficiency Standards for Clinical Pulmonary Function Laboratories. ATS statement: guidelines for the six minute walk test. Am J Respir Crit Care Med 2002;166:111-7.

34. Informe de Diálisis y Trasplante 2015. Registro Español de Enfermos Renales. Sociedad Española de Nefrología.

35. KDOQI clinical practice guideline for hemodialysis adequacy: 2015 update. National Kidney Foundation. Am J Kidney Dis 2015;66:884-930.

36. Maduell F, García M, Alcázar R. Cap 4. Dosificación y adecuación del tratamiento dialítico. Guía Centro de hemodiálisis Sociedad Española de Nefrología. 2006.

37. Delgado C, Johansen KL. Barriers to exercise participation among dialysis patients. Nephrol Dial Transplant 2012;27:1152-7.

38. Heiwe S, Tollin H. Patients' perspectives on the implementation of intra-dialytic cycling. A phenomenographic study. Implement Sci 2012;7:68.

39. Maduell F, García H, Hernández-Jaras J et al. Valoración de métodos para el cálculo del $\mathrm{Kt} / \mathrm{V}$ corregido para el rebote. Nefrologia 1997;17:55-61.

40. Maduell F, Garcia-Valdecasas J, Garcia H et al. Urea reduction ratio considering urea rebound. Nephron 1998;78:143-7.

41. Vaithilingam I, Polkinghorne KR, Atkins RC, Kerr PG. Time and exercise improve phosphate removal in hemodialysis patients. Am J Kidney Dis 2004;43:85-9.

42. Parsons TL, Toffelmire EB, King-VanVlack CE. Exercise training during hemodialysis improves dialysis efficacy and physical performance. Arch Phys Med Rehabil 2006;87:680-7.

43. Giannaki CD, Stefanidis I, Karatzaferi C et al. The effect of prolonged intradialytic exercise in hemodialysis efficiency indices. ASAIO J 2011;57:213-8.

44. Musavian AS, Soleimani A, Alavi NM, Baseri A, Savari F. Comparing the effects of active and passive intradialytic pedaling exercises on dialysis efficacy, electrolytes, hemoglobin, hematocrit, blood pressure and health-related quality of life. Nurs Midwifery Stud 2015;4:e25922. 